Journal Club

Editor's Note: These short, critical reviews of recent papers in the Journal, written exclusively by graduate students or postdoctoral fellows, are intended to summarize the important findings of the paper and provide additional insight and commentary. For more information on the format and purpose of the Journal Club, please see http://www.jneurosci.org/misc/ifa_features.shtml.

\title{
Gambling Rats and Gambling Addiction: Reconciling the Role of Dopamine in Irrationality
}

\author{
Guillaume Sescousse ${ }^{1 \star}$ and Hanneke E.M. den Ouden ${ }^{1,2 *}$ \\ ${ }^{1}$ Donders Institute for Brain, Cognition and Behaviour, Radboud University Nijmegen, $6500 \mathrm{HB}$ Nijmegen, The Netherlands, and ${ }^{2}$ Center for Neural Science \\ and Department of Psychology, New York University, New York, New York 10003 \\ Review of Cocker et al.
}

Pathological gambling is a behavioral addiction that is characterized by excessive (monetary) risk-taking in the face of negative consequences, like bankruptcy or relationship problems. Brain dopamine has been suggested to play an important role in both risky behaviors and gambling addiction. Yet, we know relatively little about the specific mechanisms that drive interindividual differences in risk attitudes, or the factors that determine whether one becomes a gambling addict. A recent study in rats (Cocker et al., 2012) investigated the relationship between dopamine and risky decision-making, using a combination of behavioral assessment, pharmacology, and brain imaging. The authors demonstrate a clear association between striatal dopaminergic transmission and the sensitivity to stake size, which they posit is linked to human pathological gambling. In this review, we critically examine the evidence supporting this link. We argue that mapping risk-taking behavior from rats to humans should be done with the utmost caution and that the sensitivity to stake size reported by Cocker et al. (2012) is different from the irratio-

\footnotetext{
Received Dec. 20, 2012; revised Jan. 15, 2013; accepted Jan. 15, 2013.

G.S. and H.E.M.d.O. received funding from the Netherlands Organisation for Scientific Research (NWO Rubicon/VENI). We thank Luke Clark, Ivan Toni, and Roshan Cools for their helpful comments.

*G.S. and H.E.M.d.O. equally contributed to this work.

Correspondence should be addressed to Guillaume Sescousse, Radboud University Nijmegen, Donders Institute for Brain, Cognition and Behaviour, 6500 HB Nijmegen, The Netherlands. E-mail: g.sescousse@donders.ru.nl.

DOI:10.1523/JNEUROSCI.5828-12.2013

Copyright $\odot 2013$ the authors $\quad 0270-6474 / 13 / 333256-03 \$ 15.00 / 0$
}

nal biases seen in human pathological gambling.

In their study, Cocker et al. (2012) assessed risk-taking in a group of 32 rats using a novel gambling task. On every trial, the rats chose between a "safe" lever delivering a known number of sugar pellets (range 1-3), versus an "uncertain" lever offering a 50/50 chance of doubling this amount or receiving nothing. Thus, for any safe option of $x$ pellets, the alternative gambling option would on average also result in $0.5^{\star} 2 x=x$ pellets, allowing the authors to assess risk attitudes in the absence of differences in the expected values of the two options. A rat that would preferentially pick the small certain reward was classified as "risk-averse," whereas a "risk-seeking" rat would prefer to gamble for the large uncertain reward. Overall, the rats showed riskseeking behavior, choosing the uncertain lever on $\sim 60 \%$ of the trials.

The authors then investigated how risk-taking was modulated between trials that differed in stake size, i.e., in the number of sugar pellets at play. While risktaking remained constant across the three stake levels in approximately two thirds of the rats, a subset of "wager-sensitive" rats changed from risk-seeking to risk-averse behavior as the stake size increased (Cocker et al., 2012, their Fig. 2A,B). The authors interpret the behavior of wagersensitive rats as irrational, because the increase in stake size did not change the relative expected value of the certain versus uncertain option.
Next, the authors studied the effect of the nonspecific dopamine enhancer amphetamine and the dopamine $\mathrm{D}_{2 / 3}$ receptor antagonist eticlopride on risk-taking behavior. Amphetamine increased overall risk-taking specifically in the wagersensitive rats, whereas eticlopride reduced risk-taking in the wager-insensitive rats (Cocker et al., 2012, their Fig. 2C-F). Notably, a $\mathrm{D}_{1}$ antagonist did not produce any detectable effects. Finally, the authors measured striatal dopamine $\mathrm{D}_{2 / 3}$ receptor density in a subset of rats $(n=9)$ using $\left[{ }^{11} \mathrm{C}\right]$ raclopride PET and autoradiography. They found a negative correlation between wager sensitivity and $\mathrm{D}_{2 / 3}$ receptor density in the dorsal striatum (Cocker et al., 2012, their Fig. 4). In the discussion, the authors propose that wager sensitivity has similarities with pathological gambling, and suggest that the association with lower striatal $\mathrm{D}_{2 / 3}$ receptor density is in line with results observed in substance addiction.

The authors linked wager sensitivity to dopamine activation of striatal $D_{2 / 3}$ receptors using a multidisciplinary approach combining behavior, pharmacological manipulations, and PET imaging. The neurobiological specificity of these results fosters important insights into individual differences in risky decision-making in rats. However, extrapolating these findings to human risk-taking and pathological gambling is problematic. First, in striking contrast to humans, the rats in this study favored the uncertain option 
in more than half of their choices. In similar contexts, humans tend to be riskaverse, with a clear preference for sure amounts of money over risky gambles of equal expected value. This behavior has been translated into a concave utility function in modern theories of risky decision-making, reflecting the idea that doubling the size of a reward does not double its subjective utility (Fox and Poldrack, 2008). Whether this discrepancy reflects intrinsic differences between species or is due to procedural differences, e.g., primary versus secondary rewards or one-shot versus repeated choices, is an open question (for a discussion, see Hayden and Platt, 2009). Nonetheless, these divergent findings emphasize the need for caution when translating results from animals to humans.

Second, the concept of irrationality as used by Cocker et al., 2012, and its link to pathology, is debatable. The authors argue that the behavior of wager-sensitive rats is irrational, because their transition from risk seeking to risk aversion as the stakes increase does not confer any real benefits. Then they link this irrational behavior to pathological gambling in humans, reasoning that irrational biases in decisionmaking set gamblers apart from healthy controls. We think this is a bold leap. A behavior is defined as irrational in terms of a deviation from a specific normative perspective that defines the translation of objective value into subjective utility. The wager-sensitive rats can be viewed as irrational if subjective utility equates to expected value, which prescribes constant risk preferences across stakes. However, their increasing risk aversion might rationally follow from an alternative utility function, for example, one that trades off expected value and risk. In fact, increasing risk aversion with increasing stakes is well documented in humans (Holt and Laury, 2002). This behavior, sometimes referred to as the "peanuts effect," can be considered adaptive, as one does not have much to lose when taking a gamble over a peanut, but probably should think twice when gambling one's house. From this perspective, the behavior of wagersensitive rats corresponds to what is typically observed in healthy humans and perhaps should therefore not be viewed as pathological.

Furthermore, even if we do regard this wager sensitivity as irrational, it is different in nature from the type of irrational behavior seen in disorders of risky decisionmaking. In pathological gambling for instance, irrationality refers to cognitive bi- ases such as illusion of control and beliefs in luck (Fortune and Goodie, 2012). These biases correspond to objectively erroneous conceptions of chance processes, as opposed to a stake-dependent risk aversion pattern. As a result of such irrational cognitive biases, pathological gamblers tend to show exacerbated risk-taking, which is the exact opposite of the behavior seen in wager-sensitive rats. For example, in probability discounting protocols, which engage the same type of decision-making under risk as in the Cocker et al. study, gamblers show a consistent shift toward risky options (Ligneul et al., 2012). As a corollary to this observation, we would like to speculate that the rats potentially at risk for gambling addiction in the Cocker et al. study are in fact those who are insensitive to wager size, or even show increased risk-taking with increasing stakes (Cocker et al., 2012, their Fig. $2 B$ ). Such a tolerance for risk at high stakes parallels one of the core symptoms of pathological gambling as defined in the DSMIV, namely the "need to gamble with increasing amounts of money to achieve the desired excitement."

This alternative view would place the observed dopamine results in a different light. Cocker et al. report a negative relationship between dopamine $\mathrm{D}_{2 / 3}$ receptor density and wager sensitivity, which they use to explain the differential effects of dopaminergic manipulations between the wager-sensitive and wager-insensitive rats. This reduction of $\mathrm{D}_{2 / 3}$ receptor density seems difficult to reconcile with our suggestion that wager-insensitive rats are those at risk for gambling addiction, since such a reduction has been consistently associated with substance addiction in humans (Volkow et al., 2010). However, it is important to note that human PET studies to date have failed to report any difference in $\mathrm{D}_{2 / 3}$ receptor availability between pathological gamblers and controls (Boileau et al., 2012; Clark et al., 2012). This suggests that the biochemical mechanisms underlying pathological gambling might be at least partly different from those identified in substance addiction.

Alternatively, pathological gambling might be modeled by heightened levels of dopamine, consistent with the psychostimulant-mimetic model of this disorder (Zack and Poulos, 2009). Support for this model comes from a recent study that looked at loss chasing, another prominent characteristic of pathological gambling in which gamblers keep increasing their bets to recover past losses. While healthy participants showed a typical increase in risk aversion with increasing stakes under placebo, they showed persistent loss chasing across stakes after administration of the dopamine enhancer methylphenidate (CampbellMeiklejohn et al., 2012). In line with these results, wager-sensitive rats in the Cocker et al. (2012) study showed increased levels of risk-seeking when administered amphetamine, while wager-insensitive rats (who we suggest might be at risk for gambling addiction) became less risk-seeking in response to the $D_{2 / 3}$ receptor antagonist eticlopride. This differential response between the two groups is further consistent with prior findings showing that dopaminergic drug effects depend on differences in baseline dopamine levels (Cools et al., 2009).

In summary, the study by Cocker et al. (2012) provides a valuable contribution to the literature on risky decision-making, demonstrating a clear link between individual differences in wager sensitivity and striatal dopamine transmission via $\mathrm{D}_{2 / 3}$ receptors. The aim of this commentary was to discuss the parallel drawn by the authors between wager sensitivity and pathological gambling, and to consider alternative explanations for the observed behavioral and pharmacological results. We argue that mapping wager sensitivity in rats to pathological gambling in humans is far from straightforward, and we speculate that any "irrationality" in gamblers may even be the reverse from what the authors suggest. Far from discouraging translational approaches, we hope that our remarks trigger discussion and foster future research focused on narrowing the gap between animal and human gambling.

\section{References}

Boileau I, Payer D, Chugani B, Lobo D, Behzadi A, Rusjan PM, Houle S, Wilson AA, Warsh J, Kish SJ, Zack M (2012) The $\mathrm{D}(2 / 3)$ dopamine receptor in pathological gambling: a PET study with [(11) C]-(+)-propyl-hexahydro-naphthooxazin and [(11) C]raclopride. Addiction. Advance online publication. Retrieved Nov. 30, 2012. doi:10.1111/add.12066. CrossRef

Campbell-Meiklejohn D, Simonsen A, ScheelKrüger J, Wohlert V, Gjerløff T, Frith $C D$, Rogers RD, Roepstorff A, Møller A (2012) In for a penny, in for a pound: methylphenidate reduces the inhibitory effect of high stakes on persistent risky choice. J Neurosci 32:1303213038. CrossRef Medline

Clark L, Stokes PR, Wu K, Michalczuk R, Benecke A, Watson BJ, Egerton A, Piccini P, Nutt DJ, Bowden-Jones $\mathrm{H}$, Lingford-Hughes AR (2012) Striatal dopamine $\mathrm{D}(2) / \mathrm{D}(3)$ receptor binding in pathological gambling is correlated with mood-related impulsivity. Neuroimage 63:40-46. CrossRef Medline

Cocker PJ, Dinelle K, Kornelson R, Sossi V, Winstanley CA (2012) Irrational choice under uncertainty correlates with lower striatal $D 2 / 3$ receptor binding in rats. J Neurosci 32:15450-15457. CrossRef Medline 
Cools R, Frank MJ, Gibbs SE, Miyakawa A, Jagust W, D'Esposito M (2009) Striatal dopamine predicts outcome-specific reversal learning and its sensitivity to dopaminergic drug administration. J Neurosci 29:1538-1543. CrossRef Medline

Fortune EE, Goodie AS (2012) Cognitive distortions as a component and treatment focus of pathological gambling: a review. Psychol Addict Behav 26:298-310. CrossRef Medline

Fox CR, Poldrack RA (2008) Prospect theory and the brain. In: Handbook of neuroeconomics
(Glimcher P, Fehr E, Camerer C, Poldrack RA, eds). San Diego: Academic.

Hayden BY, Platt ML (2009) Gambling for Gatorade: risk-sensitive decision making for fluid rewards in humans. Anim Cogn 12: 201-207. CrossRef Medline

Holt CA, Laury SK (2002) Risk aversion and incentive effects. Am Econ Rev 92:16441655. CrossRef

Ligneul R, Sescousse G, Barbalat G, Domenech P, Dreher JC (2012) Shifted risk prefer- ences in pathological gambling. Psychol Med 30:1-10. Medline

Volkow ND, Wang GJ, Fowler JS, Tomasi D, Telang F, Baler R (2010) Addiction: decreased reward sensitivity and increased expectation sensitivity conspire to overwhelm the brain's control circuit. Bioessays 32:748-755. CrossRef Medline

Zack M, Poulos CX (2009) Parallel roles for dopamine in pathological gambling and psychostimulant addiction. Curr Drug Abuse Rev 2:11-25. CrossRef Medline 